\title{
Atrazine accumulation and toxic responses in maize Zea mays
}

\author{
Xiuying $\mathrm{Li}^{1,2}$, Tong $\mathrm{Wu}^{1}$, Honglin Huang ${ }^{1}$, Shuzhen Zhang ${ }^{1, *}$ \\ 1. State Key Laboratory of Environmental Chemistry and Ecotoxicology, Research Center for Eco-Environmental Sciences, \\ Chinese Academy of Sciences, Beijing 100085, China. E-mail: xyli_st@rcees.ac.cn \\ 2. Shenyang Research Institute of Chemical Industry, Sinochem Group, Shenyang 100021, China
}

Received 22 February 2011; revised 06 April 2011; accepted 12 April 2011

\begin{abstract}
Atrazine accumulation, oxidative stress, and defense response in maize seedlings exposed to extraneous atrazine were studied. Accumulation of atrazine in maize increased with increasing exposure concentration. The abscisic acid (ABA) content was positively correlated with the atrazine concentrations in maize roots and shoots $(p<0.05)$. Hydroxyl radical $(\cdot \mathrm{OH})$ in maize was determined in vivo with electron paramagnetic resonance spectroscopy. Its intensity was positively correlated with atrazine concentration in roots and shoots $(p<0.05)$, and higher level of $\cdot \mathrm{OH}$ generated in roots than in shoots corresponded to the major accumulation of atrazine in roots. Superoxide dismutase, peroxidase and catalase in roots were up-regulated by atrazine exposure at $1 \mathrm{mg} / \mathrm{L}$ compared to the control and malondialdehyde content in roots was enhanced when atrazine exposure concentration reached $10 \mathrm{mg} / \mathrm{L}$. These results suggested the exposure and accumulation of atrazine caused oxidative toxicity and antioxidant response in maize.
\end{abstract}

Key words: atrazine; maize (Zea mays); reactive oxygen species; antioxidant enzyme; abscisic acid

DOI: $10.1016 /$ S1001-0742(11)60718-3

\section{Introduction}

As one of the most commonly detected pesticides in soil, ground and surface water, atrazine is persistent in the environment. Direct evidence showed that after 22 years under outdoor conditions, more than $50 \%$ of atrazine originally applied to soil was still detected (Jablonowski et al., 2009). Recent research has reported that atrazine even at trace level can cause adverse impact on fish, amphibians and reptilian (Rohr and McCoy, 2010). Exposure to as low as $0.1 \mu \mathrm{g} / \mathrm{L}$ of atrazine caused frogs severe health problems (Hayes, 2009). As a result, there is increasing concern about the potential ecological risk of atrazine in the environment.

When exposed to pesticide, plants usually suffer oxidative stress (Yin et al., 2008; Wang and Zhou, 2006) caused by the generation of reactive oxygen species (ROS) such as superoxide anion radical $\left(\mathrm{O}_{2}{ }^{-}\right)$, hydroxyl radical $(\cdot \mathrm{OH})$, singlet oxygen $\left({ }^{1} \mathrm{O}_{2}\right)$, and hydrogen peroxide $\left(\mathrm{H}_{2} \mathrm{O}_{2}\right)$ (Salin, 1988). Generation of $\mathrm{H}_{2} \mathrm{O}_{2}$ in roots of maize exposed to atrazine was also assayed after chemical extraction in a previous study (Nemat Alla and Hassan, 2006). The most important mechanism used by plants to prevent oxidative stress is through ROS scavenging. Studies have shown that antioxidant defense systems in plants play a key role in catalyzing ROS to water and oxygen (Noctor and Foyer, 1998). Thus measuring enzymes of antioxidant defense systems can serve as an indirect

\footnotetext{
* Corresponding author. E-mail: szzhang@rcees.ac.cn
}

method and has been frequently used to evaluate plant oxidative stress (Wang and Zhou, 2006; Song et al., 2007; Contardo-Jara and Wiegand, 2008). Nevertheless, there is little direct evidence concerning ROS generation in plants subjected to oxidative stress.

Endogenous abscisic acid (ABA) in plants plays an important role in mediating plant growth under environmental stresses such as drought, salinity tolerance and heavy metal contamination (Harris and Outlaw Jr, 1990; Maggio et al., 2007; Atici et al., 2005), which is primarily ascribed to its ability to regulate transpiration in plants. Pesticides which have a relatively high solubility are potentially transported with water and solutes upward from roots into other plant parts through the xylem. This flux is driven by the water potential gradient, created throughout the plant during transpiration (Collins et al., 2006). Therefore, we speculated that ABA might also play a key role in the transport of pesticides such as atrazine in plants by regulating transpiration in plants and thereafter protect plants against harmful effects of contamination.

The objective of the present work was therefore to investigate maize accumulation of atrazine, and oxidative stress and antioxidant responses. Concentration of atrazine was determined in maize exposed to different concentrations of atrazine. ROS generation in maize was detected in vivo by electron paramagnetic resonance (EPR) spectroscopy. The activities of superoxide dismutase (SOD), peroxidase (POD), and catalase (CAT) and lipid peroxidation expressed as equivalent of malondialdehyde (MDA) were 
measured aiming to clarify antioxidative responses of maize to atrazine contamination.

\section{Experimental}

\subsection{Chemicals}

Atrazine (purity > 97\%), $\alpha$-phenyl-N-tert-butylnitrone (PBN, purity > 98\%), and dimethylsulfoxide (DMSO, purity $>99.9 \%$ ) were purchased from Sigma-Aldrich company (USA). Methanol, dichloromethane and isopropanol used were of HPLC grade (Fisher, USA). Other reagents obtained domestically were of analytical grade (SCRC, China).

\subsection{Plant cultivation}

Maize (Zea mays L.) was used as the test plant. Seeds were purchased from the Chinese Academy of Agricultural Sciences, Beijing, China. Plant preparation was according to the method described by Zhu et al. (2007). Seeds were sterilized by soaking in $3 \% \mathrm{H}_{2} \mathrm{O}_{2}$ solution for $30 \mathrm{~min}$, followed by thoroughly washing with deionized water and subsequently germinated on moist filter paper in dark at $27^{\circ} \mathrm{C}$. Then the pre-germinated seedlings were transplanted to a container with $1 / 2$ Hoagland solution which contained the following nutrients: $4 \mathrm{mmol} / \mathrm{L} \mathrm{Ca}\left(\mathrm{NO}_{3}\right)_{2}, 1$ $\mathrm{mmol} / \mathrm{L} \mathrm{KH}_{2} \mathrm{PO}_{4}, 5 \mathrm{mmol} / \mathrm{L} \mathrm{KNO}_{3}, 2 \mathrm{mmol} / \mathrm{L} \mathrm{MgSO}_{4}$, $1 \mathrm{mmol} / \mathrm{L} \mathrm{NH} \mathrm{NO}_{3}, 50 \mu \mathrm{mol} / \mathrm{L}$ EDTA-Fe, $25 \mu \mathrm{mol} / \mathrm{L}$ $\mathrm{KI}, 50 \mu \mathrm{mol} / \mathrm{L} \mathrm{H}_{3} \mathrm{BO}_{3}, 9 \mu \mathrm{mol} / \mathrm{L} \mathrm{MnSO}_{4}, 0.77 \mu \mathrm{mol} / \mathrm{L}$ $\mathrm{ZnSO}_{4}, 0.3 \mu \mathrm{mol} / \mathrm{L} \mathrm{CuSO}{ }_{4}$ and $0.1 \mu \mathrm{mol} / \mathrm{L} \mathrm{Na}_{2} \mathrm{MoO}_{4}$. Seedlings were grown under growth chamber conditions with a day:night cycle of $16 \mathrm{hr}: 8 \mathrm{hr}$ and a temperature regime of $25^{\circ} \mathrm{C}: 20^{\circ} \mathrm{C}$. Relative humidity was maintained between $50 \%$ and $60 \%$ and a light intensity of 300 $\mu \mathrm{mol} /\left(\mathrm{m}^{2} \cdot \mathrm{sec}\right)$ photons during the whole experimental period. After cultured for 2 weeks, seedlings were exposed to Hoagland solution containing atrazine at concentrations of $1.0,2.5,5.0$, and $10.0 \mathrm{mg} / \mathrm{L}$, respectively, and hydroponically cultured for $72 \mathrm{hr}$ under the same conditions with plant preparation. Control without atrazine exposure for plants was set up and each treatment was carried out with three replicates. During atrazine exposure, the solution was replaced at each 12-hr interval in maintaining a consistent concentration. Atrazine concentration in the solution was analyzed after each exposure and the changes were less than $5 \%$ for all the determinations.

\subsection{Determination of ABA contents}

ABA in plants was analyzed according to the method of Zhou et al. (1996) and the content was quantified with an enzyme-linked immunosorbent assay (ELISA, Varioskan Flash, Thermo, USA) using reagents from China Agricultural University (China). In brief, fresh plant samples (1 g) were powdered in liquid nitrogen with the addition of cold methanol, homogenized and then centrifuged at $8000 \mathrm{r} / \mathrm{min}$ for $15 \mathrm{~min}$. In order to remove plant pigments and other non-polar compounds that might interfere with immunoassays, extracts were passed through $\mathrm{C}_{18}$ cartridges (AGT, China). The eluates were concentrated to dryness under a gentle nitrogen stream, and re-dissolved in $\mathrm{KH}_{2} \mathrm{PO}_{4}$ buffer ( $\mathrm{pH}$ 7.5) before the detection by ELISA. ABA content was expressed on a fresh weight (fw) basis.

\subsection{Determination of atrazine in plants}

Determination of atrazine in plant samples was conducted according to the method of Burken and Schnoor (1997) with minor modification. The detailed procedure was as follows: plant samples were cut and homogenized, 0.5$1.0 \mathrm{~g}$ of the subsamples (dry matter) was extracted twice with $50 \mathrm{~mL}$ of $80 \%$ aqueous methanol by shaking the suspension on a reciprocal shaker (HZQ-F160, HDL, China) for $48 \mathrm{hr}$. The extracts were filtered and combined, reduced to $5 \mathrm{~mL}$ with a rotary evaporator (RE-2000, Shyarong, China), purged to about $1-2 \mathrm{~mL}$ under a gentle nitrogen stream, and then cleaned with Florisil SPE ( $1 \mathrm{~g} / 6$ $\mathrm{mL}$, AGT, China). The eluates were evaporated, solventexchanged into methanol, and stored prior to analysis.

Atrazine in the samples were analyzed by HPLC (Agilent 1200 series, USA) equipped with an ultraviolet detector. Atrazine was determined using an Eclipse XDB$\mathrm{C}_{18}$ column $(4.6 \mu \mathrm{m} \times 150 \mathrm{~mm}, 5 \mu \mathrm{m}$ particle size, Agilent, China), a mobile phase of methanol/water $(70 / 30, V / V)$, absorbance at a wavelength of $222 \mathrm{~nm}$, and expressed on the basis of dry weight $(\mathrm{dw})$. The recovery of atrazine in the controls was $82 \%-95 \%$ and the detection limit was 5 $\mu \mathrm{g} / \mathrm{L}$.

\subsection{PBN adduct extraction and Fenton reaction}

PBN was applied as a spin trap in EPR method which was used for detection of ROS. PBN adduct in plant samples was determined according to the method of Shi et al. (2005) with some modifications. The operations were conducted in nitrogen. After rinsed with ice-cold 0.1 $\mathrm{mol} / \mathrm{L} \mathrm{CaCl}_{2}$ solution, plant samples were weighed $(0.5$ $\mathrm{g})$, homogenized in a mortar with $1.0 \mathrm{~mL}$ freshly prepared solution of $100 \mathrm{mmol} / \mathrm{L} \mathrm{PBN} \mathrm{(dissolved} \mathrm{in} \mathrm{DMSO).} \mathrm{Then}$ the homogenates were incubated at $37^{\circ} \mathrm{C}$ for $15 \mathrm{~min}$, centrifuged at $4500 \mathrm{r} / \mathrm{min}$ for $3 \mathrm{~min}$ at $4{ }^{\circ} \mathrm{C}$, and the supernatant was collected. A portion of $30 \mu \mathrm{L}$ supernatant was transferred to a capillary tube with a diameter of 1.0 $\mathrm{mm}$ for EPR analysis.

The EPR spectra were recorded with Bruker ESP 300 spectrometer (Bruker, Germany) at room temperature. The operation conditions are as follows: microwave power, 20 $\mathrm{mW}$; microwave frequency, $9.7 \mathrm{GHz}$; center field, $347 \mathrm{mT}$; scan range, $10 \mathrm{mT}$; modulation frequency, $100 \mathrm{kHz}$; modulation amplitude, $0.25 \mathrm{mT}$; and receiver gain of $2 \times 10^{4}$ scans. The intensities of free radicals were calculated based on the central peak heights of EPR signals.

\subsection{Assays of enzyme activities and lipid peroxidation}

Fresh roots or shoots $(1.0 \mathrm{~g})$ were homogenized in $10 \mathrm{~mL}$ of an extraction buffer $\left(0.05 \mathrm{~mol} / \mathrm{L} \mathrm{NaH} \mathrm{PO}_{4} \cdot \mathrm{Na}_{2} \mathrm{HPO}_{4}\right.$ in $1 \%(W / V)$ polyvinylpyrrolidone, $\mathrm{pH} 7.8)$ in an ice bath. The supernatant from the centrifuging at 10,000 $\mathrm{r} / \mathrm{min}$ for $10 \mathrm{~min}$ at $4^{\circ} \mathrm{C}$ was used for further analysis. Protein level was measured by the method of Bradford (1976) using bovine serum albumin as the standard. The 
SOD activity was measured on the basis of its ability to inhibit the photochemical reduction of nitro blue tetrazolium (Beauchamp and Fridovich, 1971). The activities of POD and CAT were determined using guaiacol and $\mathrm{H}_{2} \mathrm{O}_{2}$ substrates, respectively (Wu and von Tiedemann, 2002; Lagrimini, 1991), and expressed on the basis of protein.

The level of lipid peroxidation was determined in terms of 2-thiobarbituric acid (TBA) reactive metabolite, chiefly measuring malonaldehyde (MDA). MDA was measured as described by Liu et al. (2004) and expressed as nmol/g fw.

\subsection{Statistical analysis}

All data were expressed as mean \pm standard deviation (SD) of triplicates. Statistical analysis was performed using Origin 7.5 and SPSS 13. One-way ANOVA with Turkey's multiple comparison test was used to assess differences among samples at 0.05 level.

\section{Results and discussions}

\subsection{Atrazine accumulation and ABA contents in maize}

Concentrations of atrazine in both maize roots and shoots increased with increasing atrazine concentration in the culture solution (Table 1). Atrazine root concentration was more than 10 times higher than shoot concentration. For example, when treated with $10.0 \mathrm{mg} / \mathrm{L}$ atrazine, its concentration was $123.75 \mathrm{mg} / \mathrm{kg} \mathrm{dw}$ in roots and $11.20 \mathrm{mg} / \mathrm{kg}$ $\mathrm{dw}$ in shoots. Whereas, higher atrazine accumulation in shoots than in roots was observed in rice seedling by $\mathrm{Su}$ and $\mathrm{Zhu}$ (2006), and Turgut (2005) found that there was no significant difference in atrazine accumulation between roots and shoots of parrofeather. The different results of atrazine accumulation could be due to the use of different plant species, since distinct mechanisms control the accumulation of atrazine in target and nontarget plants (Szigeti and Lehoczki, 2003; Burken and Schnoor, 1997).

Endogenous ABA plays an important role in mediating plant growth under environmental stress. It was observed in this study that ABA contents in maize shoots and roots significantly increased with increasing exposure concentration of atrazine with an exception of $1.0 \mathrm{mg} / \mathrm{L}$ treatment for roots (Fig. 1, $p<0.05$ ). Furthermore, there is a significant positive relationship between ABA content and atrazine concentration in both maize roots and shoots $\left(R^{2}=0.988\right.$ for roots and 0.924 for shoots, $\left.p<0.05\right)$. This observation is consistent with the report by Hsu and Kao (2003). It was observed in their work that ABA was obviously induced in rice upon exposure to cadmium $(\mathrm{Cd})$,

Table 1 Accumulation of atrazine in maize tissue

\begin{tabular}{lll}
\hline $\begin{array}{l}\text { Atrazine concentration in } \\
\text { culture solution }(\mathrm{mg} / \mathrm{L})\end{array}$ & $\begin{array}{l}\text { Root } \\
(\mathrm{mg} / \mathrm{kg} \mathrm{dw})\end{array}$ & $\begin{array}{l}\text { Shoot } \\
(\mathrm{mg} / \mathrm{kg} \mathrm{dw})\end{array}$ \\
\hline 0 & nd & nd \\
1.0 & $1.54 \pm 0.10$ & $0.14 \pm 0.01$ \\
2.5 & $25.80 \pm 1.17$ & $1.40 \pm 0.07$ \\
5.0 & $50.38 \pm 3.33$ & $4.58 \pm 0.12$ \\
10.0 & $123.75 \pm 7.94$ & $11.20 \pm 0.86$ \\
\hline
\end{tabular}

Data are expressed on dry weight (dw) basis and as mean $\pm \mathrm{SD}, n=3$. nd: not detected.

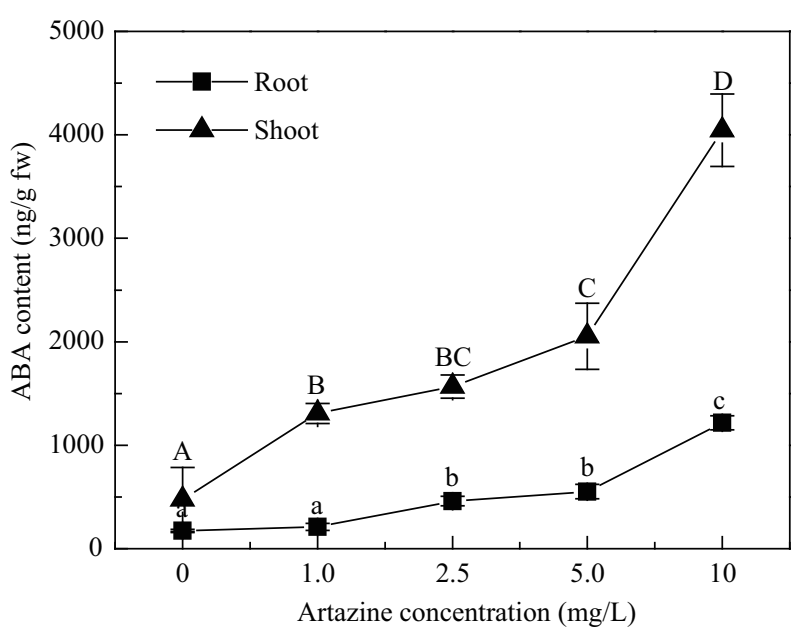

Fig. 1 Abscisic acid (ABA) contents in roots and shoots of maize subjected to atrazine exposure at different concentrations. The data was expressed on fresh weight (fw) basis. Error bars represent SD values. Different letters indicate significant differences at $p<0.05$, the lowercase letters and the upper-case letters indicate differences in maize roots and shoots, respectively.

and the elevated ABA contents exerted regulatory effects on transpiration, thereafter reducing the transportation and toxicity of $\mathrm{Cd}$ in rice. Atrazine is solely transported by xylem (Francisco, 2001). Thus, we can expect that, similar to $\mathrm{Cd}$, elevated ABA content will reduce transpiration rate, thereby limit transportation of atrazine from roots to shoots and reducing atrazine toxicity.

\subsection{ROS generation in maize}

Increasing exposure concentration of atrazine resulted in the increase of the EPR signal of PBN radical adducts in both maize roots and shoots (Fig. 2). The hyperfine coupling constants of the PBN adducts were $\alpha^{\mathrm{N}}=14.9$ $\mathrm{G}, \alpha^{\mathrm{H}}=2.9 \mathrm{G}, \alpha^{\mathrm{N}}=16.2 \mathrm{G}, \alpha^{\mathrm{H}}=3.5 \mathrm{G}$ and $\mathrm{g}=2.0062$, which correspond to that of $\mathrm{PBN} /$ methoxy radical $\left(\cdot \mathrm{OCH}_{3}\right)$ and $\mathrm{PBN} /$ methyl radical $\left(\cdot \mathrm{CH}_{3}\right)$, respectively (Shi et al., 2005). PBN itself was examined and no EPR signal was observed (Fig. 2). It was reported that hydroxyl radical $(\cdot \mathrm{OH})$ reacted with DMSO to produce $\cdot \mathrm{CH}_{3}$ (Takeshita et al., 2004). Because oxygen cannot be completely secluded under anaerobic condition, the $\cdot \mathrm{CH}_{3}$ may be oxidized to - $\mathrm{OCH}_{3}$ (Yin et al., 2007). Methyl gallate could scavenge $\cdot \mathrm{OH}$, but could not scavenge $\cdot \mathrm{CH}_{3}$ (Takeshita et al., 2004). When $0.2 \mathrm{~mL}$ of $1 \mathrm{~mol} / \mathrm{L}$ methyl gallate was added to the homogenized plant tissue prior to the addition of PBN and DMSO, the signals of PBN adducts were totally inhibited (data not shown). Consequently, the signal of ROS captured in this study was recognized as $\cdot \mathrm{OH}$.

The intensity of the EPR signal represents the ROS level, and the $\cdot \mathrm{OH}$ intensity was calculated by the signal intensity of the second couple of the triplet and listed in Table 2. Weak signals of $\cdot \mathrm{OH}$ were found in both roots and shoots of maize without atrazine exposure, indicating - $\mathrm{OH}$ generation during normal cellular functions (Yin et al., 2007). Similar to the results of higher atrazine accumulation in roots than in shoots, more $\cdot \mathrm{OH}$ was detected in maize roots than in shoots. Furthermore, the $\cdot \mathrm{OH}$ intensity was positively correlated with atrazine concentration in 

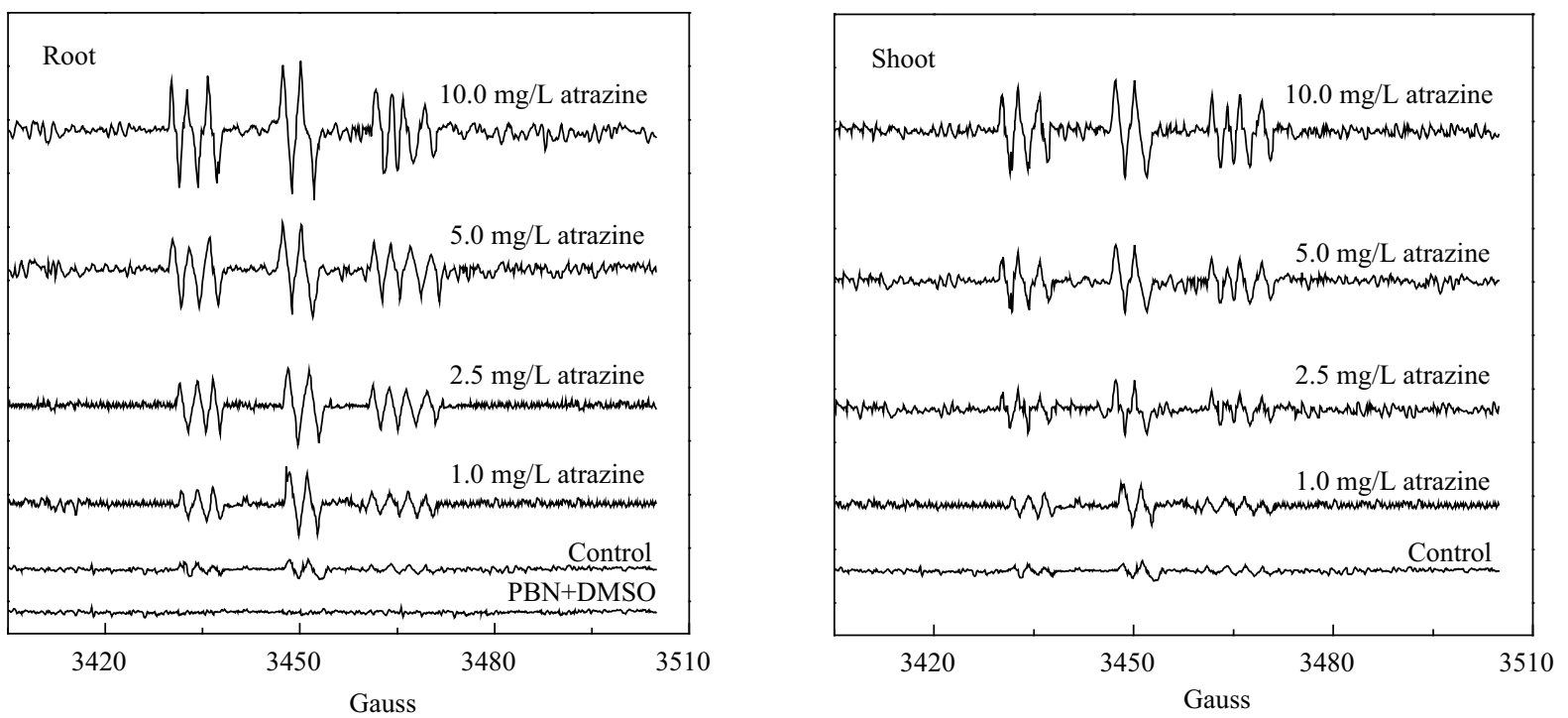

Fig. 2 EPR detection of $\alpha$-phenyl-N-tert-butylnitrone adducts in maize roots and shoots after atrazine exposure.

Table 2 Reactive oxygen species generation in maize tissues

\begin{tabular}{lll}
\hline $\begin{array}{l}\text { Atrazine concen- } \\
\text { tration }(\mathrm{mg} / \mathrm{L})\end{array}$ & \multicolumn{2}{l}{ Hydroxyl radical intensity (arbitrary unit)* } \\
\cline { 2 - 3 } & Root & Shoot \\
\hline 0 & $9.05 \pm 0.36 \mathrm{a}$ & $8.05 \pm 0.29 \mathrm{~A}$ \\
1.0 & $30.49 \pm 2.11 \mathrm{~b}$ & $19.03 \pm 1.15 \mathrm{~B}$ \\
2.5 & $36.25 \pm 2.99 \mathrm{~b}$ & $26.51 \pm 1.98 \mathrm{C}$ \\
5.0 & $45.38 \pm 3.45 \mathrm{c}$ & $32.47 \pm 2.51 \mathrm{D}$ \\
10.0 & $61.74 \pm 4.52 \mathrm{~d}$ & $44.36 \pm 3.14 \mathrm{E}$ \\
\hline
\end{tabular}

* Data are expressed as mean $\pm \mathrm{SD}, n=3$. Different letters indicate significant differences at $p<0.05$, the lower-case letters and the uppercase letters indicate differences in maize roots and shoots, respectively.

maize $\left(R^{2}=0.985\right.$ for roots and 0.855 for shoots, $p<$ $0.05)$, meaning that atrazine stimulates production of $\cdot \mathrm{OH}$ in plants. $\cdot \mathrm{OH}$ is the most reactive species among the ROS. It immediately reacts with surrounding target molecules after generated. Concentration- and time-dependent effects of atrazine exposure on $\mathrm{H}_{2} \mathrm{O}_{2}$ generation in maize Giza 2 have been observed (Nemat Alla and Hassan, 2006), also suggesting the existence of oxidative stress in maize by atrazine. The induction of ROS by atrazine may be due to the biochemical functions of atrazine in plants. Atrazine can block the flow of electrons through photosystem II to the photosystem I reaction center. The excited chlorophy II molecules reacts with $\mathrm{O}_{2}$ to form singlet oxygen $\left({ }^{1} \mathrm{O}_{2}\right)$, inducing the formation of ROS including $\mathrm{O}_{2} \cdot{ }^{-}$radical,
$\mathrm{H}_{2} \mathrm{O}_{2}$ and $\cdot \mathrm{OH}$ (Mittler, 2002; Nemat Alla and Hassan, 2006). Accumulation of ROS in maize indicated oxidative stress induced by atrazine.

\subsection{Antioxidative responses and lipid peroxidation}

Treatments with extraneous atrazine (1.0-10.0 mg/L) resulted in a significant increase in both contents of SOD and POD in maize roots compared to the control ( $p<$ 0.05) (Fig. 3). The CAT activity in roots also increased with increasing atrazine concentration in the solution. The yield effects were statistically significant, but they were numerically small (Fig. 3). However, for maize shoots, significant increases of SOD, POD, and CAT activities were only observed when atrazine concentration was 10.0 $\mathrm{mg} / \mathrm{L}$.

In order to defend against oxidative damage induced by ROS, the antioxidant defense systems operate with the sequential and simultaneous actions of a number of enzymes including SOD, POD, and CAT. Enhanced production of $\cdot \mathrm{OH}$ might generate $\mathrm{O}_{2}{ }^{-}$and $\mathrm{H}_{2} \mathrm{O}_{2}$, and the SOD activity in maize was increased as an antioxidant response to protect the plants. SOD is the first stage enzyme that removes $\mathrm{O}_{2}{ }^{\cdot-}$ radicals generated from normal physiological activities and exposure to oxidative stress (Bowler et al., 1992). It can catalyze the disproportionation
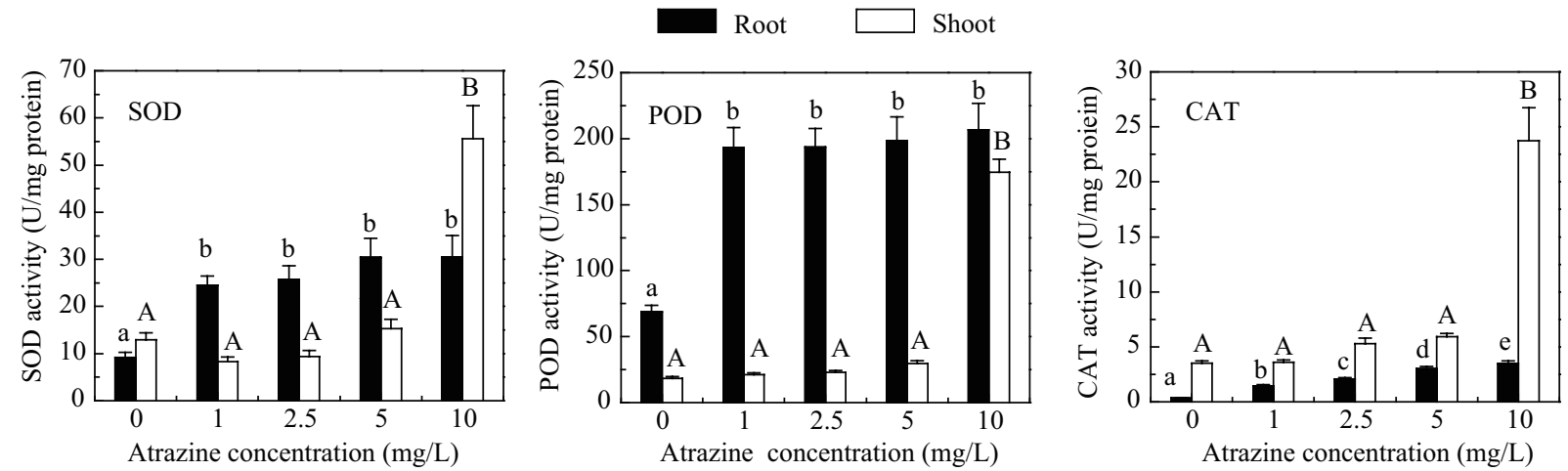

Fig. 3 Activities of SOD, POD, and CAT in roots and shoots of maize exposed to atrazine at different concentrations. Error bars represent SD values. Different letters indicate significant differences at $p<0.05$, the lower-case letters and the upper-case letters indicate differences in maize roots and shoots, respectively. 
of two $\mathrm{O}_{2}{ }^{-{ }^{-}}$radicals to $\mathrm{H}_{2} \mathrm{O}_{2}$ and $\mathrm{O}_{2}$ and probably plays a key role in reducing toxic ROS accumulation (Salin, 1988). As an effective reaction of antioxidant enzyme systems, induction of SOD usually coincided with the increased activities of POD and CAT which are important $\mathrm{H}_{2} \mathrm{O}_{2}$ scavengers by catalyzing $\mathrm{H}_{2} \mathrm{O}_{2}$ to water and oxygen. The POD and CAT activities were enhanced in roots for all atrazine treatments and in shoots of $10.0 \mathrm{mg} / \mathrm{L}$ atrazine exposed maize. POD is generally considered as one of the effective enzymes in antioxidant defense systems because its extra- and intra-cellular forms are all participating in the breakdown of $\mathrm{H}_{2} \mathrm{O}_{2}$ (Foyer et al., 1994). The responses of SOD and POD in roots observed in this study were consistent with the observations of maize shoots exposed to spraying atrazine (Hassan and Nemat Alla, 2005; Beker and Yigit, 2010), demonstrating that atrazine exposure induces antioxidant and detoxification responses in maize. The relatively high accumulation of atrazine in roots was most likely responsible for the higher level of $\cdot \mathrm{OH}$ and antioxidant enzyme activities in roots than in shoots. The increases of the three enzymes were shown to be atrazine concentration-dependent. Only a relatively high exposure concentration of atrazine (such as $10.0 \mathrm{mg} / \mathrm{L}$ in this study) would result in its accumulation in shoots high enough to induce antioxidant enzymes.

When ROS is generated in excess or the cellular antioxidant defense is deficient, it can stimulate free radical chain reactions and cause lipid peroxidation. Generally, measuring MDA is one of the most commonly applied assays to determine the extent of lipid oxidation (Halliwell and Chirico, 1993). The accumulation of MDA suggests the lipid peroxidation in plants. In this study, the MDA content in maize roots was significantly increased only when the exposure atrazine concentration was $10.0 \mathrm{mg} / \mathrm{L}$ $(p<0.05)$ (Fig. 4), while there was no significant difference in MDA level in maize shoots between the atrazine treatment and control ( $p>0.05)$ (Fig. 4). The results in this study suggested that oxidative stress induced by

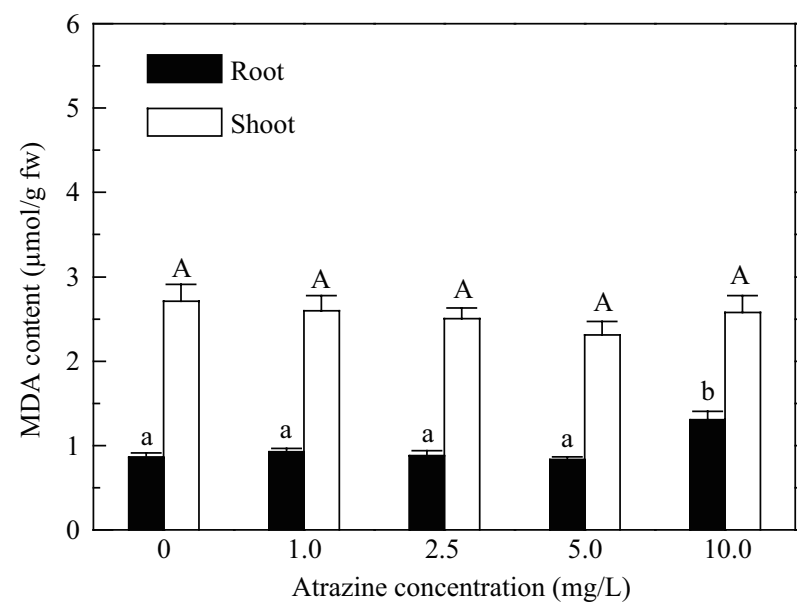

Fig. 4 Malondialdehyde (MDA) concentration in roots and shoots of maize exposed to atrazine at different concentrations. The data was expressed on fresh weight (fw) basis. Error bars represent SD values. Different letters indicate significant differences at $p<0.05$, the lowercase letters and the upper-case letters indicate differences in maize roots and shoots, respectively.
-OH caused lipid peroxidation and irreversible damage in maize roots when exposure concentration of atrazine was as high as $10.0 \mathrm{mg} / \mathrm{L}$. Efficient scavenges of ROS by antioxidant enzymes protected cell membrane from attacking by ROS for maize exposed to atrazine stress. The induction and cooperation of antioxidant enzymes in maize played an important role in detoxification of atrazine and counteract oxidative stress. Detected ROS in shoots of maize exposed to atrazine at concentrations below 10.0 $\mathrm{mg} / \mathrm{L}$ might mainly play as signaling molecules and did not cause lipid peroxidation.

\section{Conclusions}

Exposure to atrazine caused its accumulation in maize and oxidative stress confirmed by in vivo detection of ROS generation. Endogenous ABA played a role in reducing atrazine transportation in maize. Oxidative stress activated the antioxidant defense mechanism. The antioxidant enzymes SOD, POD and CAT in roots were up-regulated compared to the control when maize exposed to atrazine at concentration of $1.0 \mathrm{mg} / \mathrm{L}$. However, only when atrazine concentration was as high as $10.0 \mathrm{mg} / \mathrm{L}$, these activities in shoots were significantly induced. This study demonstrates that atrazine mainly accumulates in maize roots and - OH generation and detoxification by antioxidant enzymes SOD, POD, and CAT also primarily occur in roots. This study suggests that combined information on contaminant accumulation, toxicity stress and antioxidant response is crucial to evaluate the influence of contamination on plants.

\section{Acknowledgments}

This work was supported by the National Basic Research Program of China (No. 2009CB421603) and the National Natural Science Foundation of China (No. 40730740, 20921063).

\section{References}

Atici Ö, Ağar G, Battal P, 2005. Changes in phytohormone contents in chickpea seeds germinating under lead or zinc stress. Biologia Plantarum, 49(2): 215-222.

Beauchamp C, Fridovich I, 1971. Superoxide dismutase: improved assays and an assay applicable to acrylamide gels. Analytical Biochemistry, 44(1): 276-287.

Beker A G, Yigit E, 2010. The changes in some biochemical parameters in Zea mays cv. "Martha F1" treated with atrazine. Ecotoxicology and Environmental Safety, 73(6): 1429-1432.

Bowler C, Van Montagu M, Inze D, 1992. Superoxide dismutase and stress tolerance. Annual Review of Plant Physiology and Plant Molecular Biology, 43(1): 83-116.

Bradford M M, 1976. A rapid and sensitive method for the quantitation of microgram quantities of protein utilizing the principle of protein-dye binding. Analytical Biochemistry, 72(1-2): 248-254.

Burken J G, Schnoor J L, 1997. Uptake and metabolism of atrazine by poplar trees. Environmental Science and Technology, 31(5): 1399-1406. 
Collins C, Fryer M, Grosso A, 2006. Plant uptake of non-ionic organic chemicals. Environmental Science and Technology, 40(1): 45-52.

Contardo-Jara V, Wiegand C, 2008. Biotransformation and antioxidant enzymes of Lumbriculus variegates as biomarkers of contaminated sediment exposure. Chemosphere, 70(10): $1879-1888$.

Foyer C H, Descourvieres P, Kunert K J, 1994. Protection against oxygen radicals: an important defence mechanism studied in transgenic plants. Plant, Cell and Environment, 17(5): 507-523.

Francisco F, 2001. Physiological mechanism of herbicide action. In: Handbook of Plant and Crop Physiology (Pessarakli M, ed.). Marcel Dekker Inc., New York. 773-783.

Halliwell B, Chirico S, 1993. Lipid peroxidation: its mechanism, measurement, and significance. The American Journal of Clinical Nutrition, 57(5): 715s-725s.

Harris M J, Outlaw W H Jr, 1990. Histochemical technique: A low-volume, enzyme-amplified immunoassay with subfmol sensitivity. Application to measurement of abscisic acid in stomatal guard cells. Physiologia Plantarum, 78(3): 495-500.

Hassan N M, Nemat A M M, 2005. Oxidative stress in herbicidetreated broad bean and maize plants. Acta Physiologiae Plantarum, 27(4A): 429-438.

Hayes T, 2009. More feedback on whether atrazine is a potent endocrine disruptor chemical. Environmental Science and Technology, 43(16): 6115.

Hsu Y T, Kao C H, 2003. Role of abscisic acid in cadmium tolerance of rice (Oryza sativa L.) seedlings. Plant, Cell and Environment, 26(6): 867-874.

Jablonowski N D, Köppchen S, Hofmann D, Schäffer A, Burauel $\mathrm{P}, 2009$. Persistence of ${ }^{14} \mathrm{C}$-labeled atrazine and its residues in a field lysimeter soil after 22 years. Environmental Pollution, 157(7): 2126-2131.

Lagrimini L M, 1991. Wound-induced deposition of polyphenols in transgenic plants overexpressing peroxidase. Plant Physiology, 96(2): 577-583.

Liu P C, Wang H, Cheng J Q, Huang J C, 2004. Regulation of nitric oxide on drought-induced membrane lipid preoxidation in wheat leaves. Acta Botanica Boreali-Occidentalia Sinica, 24(1): 141-145.

Maggio A, Raimondi G, Martino A, De Pascale S, 2007. Salt stress response in tomato beyond the salinity tolerance threshold. Environmental and Experimental Botany, 59(3): 276-282.

Mittler R, 2002. Oxidative stress, antioxidants and stress tolerance. Trends in Plant Science, 7(9): 405-410.

Nemat A M M, Hassan N M, 2006. Changes of antioxidants levels in two maize lines following atrazine treatments. Plant Physiology and Biochemistry, 44(4): 202-210.

Noctor G, Foyer C H, 1998. Ascorbate and glutathione: keeping active oxygen under control. Annual Review of Plant Physiology and Plant Molecular Biology, 49(1): 249-279.
Rohr J R, McCoy K A, 2010. A qualitative meta-analysis reveals consistent effects of atrazine on freshwater fish and amphibians. Environmental Health Perspectives, 118(1): 20-32.

Salin M L, 1988. Toxic oxygen species and protective systems of the chloroplast. Physiologia Plantarum, 72(3): 681689.

Shi H H, Wang X R, Luo Y, Su Y, 2005. Electron paramagnetic resonance evidence of hydroxyl radical generation and oxidative damage induced by tetrabromobisphenol $\mathrm{A}$ in Carassius auratus. Aquatic Toxicology, 74(4): 365-371.

Song N H, Yin X L, Chen G F, Yang H, 2007. Biological responses of wheat (Triticum aestivum) plants to the herbicide chlorotoluron in soils. Chemosphere, 68(9): 1779-1787.

Su Y H, Zhu Y G, 2006. Bioconcentration of atrazine and chlorophenols into roots and shoots of rice seedlings. Environmental Pollution, 139(1): 32-39.

Szigeti Z, Lehoczki E, 2003. A review of physiological and biochemical aspects of resistance to atrazine and paraquat in Hungarian weeds. Pest Management Science, 59(4): 451458.

Takeshita K, Fujii K, Anzai K, Ozawa T, 2004. In vivo monitoring of hydroxyl radical generation caused by X-ray irradiation of rats using the spin trapping/EPR technique. Free Radical Biology and Medicine, 36(9): 1134-1143.

Turgut C, 2005. Uptake and modeling of pesticides by roots and shoots of parrotfeather (Myriophyllum aquaticum). Environmental Science and Pollution Research, 12(6): 342346.

Wang M E, Zhou Q X, 2006. Effects of herbicide chlorimuronethyl on physiological mechanisms in wheat (Triticum aestivum). Ecotoxicology and Environmental Safety, 64(2): 190-197.

Wu Y X, von Tiedemann A, 2002. Impact of fungicides on active oxygen species and antioxidant enzymes in spring barley (Hordeum vulgare L.) exposed to ozone. Environmental Pollution, 116(1): 37-47.

Yin X L, Jiang L, Song N H, Yang H, 2008. Toxic reactivity of wheat (Triticum aestivum) plants to herbicide isoproturon. Journal of Agricultural and Food Chemistry, 56(12): 48254831.

Yin $\mathrm{Y}$, Jia $\mathrm{H} \mathrm{X}$, Sun $\mathrm{Y}$ Y, Yu H X, Wang X R, Wu J C et al., 2007. Bioaccumulation and ROS generation in liver of Carassius auratus, exposed to phenanthrene. Comparative Biochemistry and Physiology Part C: Toxicology and Pharmacology, 145(2): 288-293.

Zhou X, Zheng Z F, Chen P Y, Zhang D, 1996. Preparation and application of monoclonal antibodies specific for abscisic acid methyl ester. Acta Phytophysiologica Sinica, 22(3): 284-290.

Zhu Y H, Zhang S Z, Zhu Y G, Christie P, Shan X Q, 2007. Improved approaches for modeling the sorption of phenanthrene by a range of plant species. Environmental Science and Technology, 41(22): 7818-7823. 